\title{
De histérica inválida a escritora transgresora: el caso de Alice James y la superación de los límites
}

\author{
From Being an Hysteric Invalid To Be a Transgressive \\ Writer: Alice James' Example of Going Beyond the Limits
}

\begin{abstract}
RESUMEN
La histeria, un tema ampliamente estudiado, aunque solo parcialmente superado, supuso una opresión de las mujeres por el hecho de ser mujeres. Si bien hoy ha desaparecido como categoría médica, sus implicaciones psicológicas y sociales siguen presentes. Su «época dorada» fue el siglo XIX, cuando mujeres como Alice James sufrieron todo el peso de la maquinaria del patriarcado a través de su enfermedad: una invalidez que la postró en cama durante más de la mitad de su penosa vida. Determinar la etiología de su dolencia es tarea ardua, pues se ven representadas una familia contradictoria con un padre misógino, una sociedad de férreo control y domesticación femeninos como la victoriana y una suerte de «disposición psicológica» de nuestra protagonista. Alice tuvo la valentía necesaria para rebelarse, transgredir las normas impuestas y regalarnos una parte de sí misma: su Diario.

Palabras clave: histeria, patriarcado, Alice James, transgresión.
\end{abstract}

\begin{abstract}
Hysteria, a widely studied topic, if only partially overcome, meant oppression of women only because they (we) are women. While it has now disappeared as a medical category, psychological and social implications remain. Its «Golden Age» was the nineteenth century, when women like Alice James suffered the full weight of the machinery of patriarchy through their illness: a disability that fell on the bed for more than half of her sorry life. Determine the ethiology of their condition is not an easy work, since she lived in an weird family with a misogynistic father, a society of strict control and domestication as Victorian one and a kind of "psychological readiness» of our protagonist. Alice had the courage to rebel, breaking the rules imposed and giving us an intimate part of herself: her Diary.
\end{abstract}

Keywords: histeria, patriarchy, Alice James, transgression.

\section{SUMARIO}

1. Introducción. 2. Una época histérica. 3. A modo de ejemplo: Alice James. 4. La superación de los límites. 5. Consideraciones finales: ¿qué hemos aprendido? 6. Bibliografía.

\section{Introducción}

La histeria fue una de las principales causas de locura durante el siglo XIX. La histeria -femenina-, una represión sufrida por las mujeres fue conocida con diferentes nombres -histeria, postración nerviosa, neurastenia,... Fue un síntoma no de aquellas -muchas- que la padecían, sino de su época. La mujer decimonónica

1 Departamento de Filosofía (UNED); alma.lv.12@gmail.com.

ASPARKÍA, 29; 2016, 145-160 - ISSN: 1132-8231 - DOI: HTTP:/ / DX.DOI.ORG/10.6035/AsPARKIA.2016.29.10 
y, más concretamente, la mujer victoriana representa el culmen de la dominación masculina sobre una construcción de la feminidad insoportable. La exagerada domesticación de las mujeres trajo consigo su rebelión.

Sin embargo, antes de que esta paulatina liberación de las mujeres pudiese comenzar, la humanidad -entiéndase, los hombres- dibujó la historia de una represión. La histeria marcó un límite rígido, que se pensaba inamovible entre lo sano y lo patológico, lo masculino y lo femenino, así como lo público y lo privado (Pateman, 1996). Estos pares de «opuestos» han de ser entendidos tal y como el patriarcado vino construyendo a lo largo de los siglos, resultando en una concepción de lo sano como masculino y público, mientras que lo patológico era femenino y privado. Tan profundo grabó sus trazos, que todavía hoy, más de un siglo después de que se iniciasen las modificaciones encaminadas a borrar sus huellas, la desigualdad sigue presente.

En este trabajo pretendemos mostrar cómo las mujeres han luchado por borrar esas desigualdades que las oprimían. Para ello ha hecho falta un largo camino, representado en muchas ocasiones por personajes icónicos del feminismo. Gracias a ejemplos tan diferentes de mujeres como -y mencionando azarosamente algunas de ellas- las escritoras feministas Charlotte Perkins Gillman, Edith Wharton o Kate Chopin, y a teóricas del feminismo y ensayistas como Betty Friedan, Kate Millet o Simone de Beauvoir se ha avanzado en igualdad, pero queda un largo sendero por recorrer. Lejos de pretender desmerecer su legado o establecer odiosas comparaciones, entre nuestros objetivos nos hemos marcado uno más modesto: el hacer ver cómo otras mujeres menos visibilizadas también han contribuido con su grano de arena. Este es el caso de Alice James, quién si bien no supuso un gran cambio para el devenir de las mujeres, sí realizó su propio acto de transgresión. Además de hacer visible a una mujer olvidada, el caso de Alice constituye una base de análisis que permita desentrañar cómo la etiqueta de histeria todavía continúa condicionando la sociedad actual.

Alice James fue una «loca», una «inválida», cuya escritura es el hito más sobresaliente de una vida de transgresión -invertida, desde dentro- contra esa opresión. Su ejemplo no es un caso aislado, sino que representa un colectivo de mujeres que durante el siglo XIX utilizaron la única arma que tenían a su alcance: la enfermedad. Tenemos la suerte de que nos ha regalado una parte de sí misma, de su modo de pensar y de sentir, plasmados en su Diario.

Comenzando por contextualizar históricamente la histeria y su desarrollo, pasaremos a apuntar la situación de la época de Alice: segunda mitad del siglo XIX. Siendo un siglo de profunda convulsión en pro de los derechos humanos -al menos de una parte, la proletaria, de la humanidad- la represión de las mujeres, como de otros colectivos, fue quizás más férrea que nunca. Como ejemplo de esta opresión, pero también de la nueva y creciente actitud de defensa de su libertad por parte de las mujeres, veremos el caso de Alice James. La pasividad de la autora ante la vida que otros eligieron para ella chocó con una fuerte personalidad, dando como resultado su invalidez. Su bello y crítico texto, su Diario, no fue aceptado por los tolerantes hermanos. Para finalizar, sacaremos algunas reflexiones acerca de lo que 
enseña una mujer como Alice y cuánto trabajo está todavía pendiente. Lamentablemente, más de lo que parece.

El siglo XIX supone un cambio de rumbo en muchos aspectos. Uno de ellos que, pese a sus hondas implicaciones, no suele ser tomado demasiado en serio fue la revolución femenina. No obstante, a poco que echemos la vista atrás y pese a los intentos de ocultación, en todas las épocas hubo voces disonantes. Desde los albores de la civilización Occidental las mujeres estuvieron reprimidas y, especialmente entre los siglos XI y XVII, aquellas que osaban transgredir las normas, obtuvieron los más diversos y horrendos castigos.

\section{Una época histérica}

El patriarcado contó -y cuenta- con las más diversas herramientas para mantener sometido a un colectivo tan "genérico» como las mujeres. Uno de los más eficaces instrumentos fue una patología: la histeria.

El surgimiento de esta patología se remonta a, al menos, el antiguo Egipto. Se tiene constancia documental ya en torno al año 1900 a.C. en el Kahun Papyrus. El más importante de estas fuentes es, sin duda, «el mejor documento médico egipcio», el Papyrus Ebers, en dónde se relaciona la histeria con el «hambre» del útero, pudiendo remediarse fumigando con olorosas substancias el cuerpo "para causar que el útero de la mujer fuese a su sitio» (Papyrus Ebers, 1937: 108-109).

Durante su larga existencia tanto la enfermedad como su causa -el útero- recorrieron diversas partes del cuerpo, hasta llegar a ser un problema mental hacia el siglo XIX (Veith, 1965). El cambio se produjo debido a diferentes factores, entre los que encontramos el mayor conocimiento del cuerpo, gracias a los estudios anatómicos emprendidos desde el Renacimiento, o el auge de la Razón, frente a la religión, desarrollado tanto desde las ciencias empíricas como desde la filosofía. Estas nuevas características dieron como resultado que el elemento humano más vulnerable fuese la mente y que ya no pudiese, además, sostenerse la histeria como patología corporal.

Además, con este auge de la Razón y la mente, se produce una desnaturalización de las relaciones sexuales, que vendrá a reforzar las diferencias de género establecidas. Mientras en la medicina griega éstas eran necesarias y durante el medievo, siempre que fuesen matrimoniales, recomendables, desde la Modernidad va a suponer un gasto de energías que restan potencia a la Razón. Galeno, por ejemplo, pese a considerar que la mujer sin un hombre padecería esta enfermedad, "reconoce que esta enfermedad se produce sobre todo entre las viudas, $y$, sobre todo en aquellas que han sido regulares en su menstruación antes de su viudez, fértiles y receptivas y con ganas de sus maridos»(Galeno, 1997: 42). Es decir, las relaciones sexuales son concebidas como algo natural y necesario, aunque, advierte, no se deben confundir la función sexual, necesaria, y el erotismo, que resultaba innecesario y estaría prácticamente ausente (Garrison, 1963).

Lo mismo ocurre durante la Época Medieval, período en el cual se ha de conjugar la idea de celibato y la necesidad de una procreación abundante que propor- 
cionase los recursos que garantizaban el nivel de vida de los señores feudales y la Iglesia. La solución a esta cuestión pasa por restringir las relaciones sexuales al matrimonio, dentro del cual eran consideradas beneficiosas, naturales y necesarias. No obstante, si las mujeres se mostraban excesivamente lascivas, activas, o sabias, se las acusaba de brujería. Así, mientras que:

...la posesión por un demonio era un accidente y no un crimen. Cristo no había castigado a endemoniados, sino que los había curado por expulsión de los malos espíritus. Con la creencia en la brujería, sin embargo, se asumió que las brujas habían sido seducidas por el diablo o habían pactado con él: ellas se habían hecho infieles y su delito era la herejía. Como herejes no fueron tratadas, sino castigadas (Sigerist, 1943: 82-83).

La creencia en los castigos divinos o las posesiones demoníacas, sin embargo, fue progresivamente eliminada a partir de lo que se conoce como Revolución Científica. Los problemas divinos pasaron a ser problemas mentales (Turró, 1985: 3738). Esta época es, también, la del nacimiento del Estado Moderno y, con él, la idea de Estado de Bienestar. ¿Bienestar para quién?, cabría preguntarse. Para los hombres, es más, para los hombres, occidentales, blancos y con un cierto nivel económico. Tal y como Pateman ha puesto brillantemente de manifiesto, en esta época, también, se hizo:

...hincapié en cómo las circunstancias personales están estructuradas por factores públicos, por leyes sobre la violación y el aborto, por el estatus de «esposa», por políticas relativas al cuidado de las criaturas y por la asignación de subsidios propios del Estado de bienestar y por la división sexual del trabajo en el hogar y fuera de él. Por tanto, los problemas «personales» sólo se pueden resolver a través de medios y de acciones políticas (Pateman, 1996: 46-47).

En el siglo XIX, por ejemplo, se creía que cada individuo poseía una cantidad de energía limitada para cada día, por lo que una mujer lasciva -es decir, sexualmente activa- era peligrosa. El culmen de esta represión sexual fue la época victoriana (Makari, 2012), durante la cual cualquier muestra de sentimientos era vista con desconfianza.

Una de las características de esta época es común a la larga historia de represión de las mujeres desde la Antigüedad: el confinamiento. El ostracismo social fue uno de los grandes impedimentos puestos a mujeres que ostentaron alguna función social más allá de los límites de su casa, como curanderas o matronas, por ejemplo. Los conocimientos reunidos por estas mujeres y la relativa independencia económica y familiar de la que muchas gozaban las llevó a ser consideradas peligrosas para el orden social establecido.

Esta preocupación ya había sido despertada en la Modernidad por todos aquellos..., (considerada aquí, por razones prácticas, como el período entre los siglos XVI y XVIII) por todos aquellos «locos» y «anormales», cuya función socialmente limítrofe fue la de mantener el orden social (Foucault, 2006) y la diferenciación 
entre lo «normal» y lo «patológico» (Canguilhem, 2005). Las mujeres rebeldes, poderosas, desviadas, se vuelven una patología social. La histeria se vuelve a ojos de los doctores, entonces, síntoma de la rebelión de las mujeres y no de su enfermedad (Showalter, 1985: 145).

Unido a lo anterior y siendo la mujer tanto el foco de los males, como la mitad mentalmente débil de la humanidad, la histeria se convirtió en el mal de una época. Las histéricas no eran las mujeres, sino la sociedad en las que les tocó vivir (Montiel, 2006). Una cultura con un amplio abanico de nuevas posibilidades y desarrollo que, sin embargo, no les permitía a ellas realizar nada fuera del ámbito tradicional del hogar, el matrimonio y los hijos. «Lou» May Alcott relata cómo, a pesar de contar con el apoyo de alguien de la talla Emerson o Thoureau, se enfrentó a diversas dificultades y reticencias a que sus obras fuesen publicadas por el mero hecho de ser mujer (Feito, 2005). La autora de Mujercitas afirmó reiteradamente que «la libertad es el mejor marido» (Feito, 2005: 58), mientras que Alice James comprende que, en su época, «el matrimonio parece ser la única ocupación fructuosa para una mujer» (Feinstein, 1987: 278).

Incluso aquellas que pasaron a hacerse un pequeño hueco en la historia «masculina», sufrieron las consecuencias. Tal es el celebérrimo caso de Charlotte Perkins Gillman, cuyos costes psicológicos y personales de su independencia y rebeldía son notoriamente conocidos. Podemos poner, aún, otro ejemplo más sutil, pero igualmente significativo. En Una mirada atrás, Edith Warthon nos relata cómo, a pesar de haber tenido «suerte» con un matrimonio abierto e igualitario, sentía el rechazo social que generaba el ser una mujer culta, famosa e independiente (Wharton, 1997: 166).

Sin embargo, algunas otras mujeres fueron conocidas meramente por su vinculación con la histeria, la charlatanería y la desviación social que suponían. Con ello nos referimos a casos como los de las célebres médiums la vidente de Prevost, las hermanas Fox ó Mrs. Piper (Moore, 1977). Estas mujeres representaron un fenómeno social que pasa hoy desapercibido, lo que aumenta su asociación con la patología mental. Las visiones, creencias e investigaciones acerca de fantasmas estaban a la orden del día, siendo una característica fundamental en la sociedad decimonónica.

Sin embargo, pese a existir algunos intentos sistemáticos y objetivos de acercarse a estas mujeres, como los emprendidos por la Society of Psychical Research, las médiums fueron consideradas como histéricas por el conjunto de la medicina de la época, atrayendo al más diverso público, pero sin ser aceptadas por él. Además, cualquier relación con fantasmas y aparecidos se presenta en la actualidad como fortuita, ridiculizando a posteriori a aquellas mujeres que, mediante esas experiencias, lograban cierta fama y canalizaban su energía reprimida.

Pero existe todavía un tercer grupo de mujeres que han de ser consideradas y que podemos denominar «las olvidadas». Entre aquellas que no tuvieron posibilidad de ser visibles, de desarrollarse y ser autónomas, de enfrentarse al sistema imperante o que fueron silenciadas por él, encontramos un caso excepcional: Alice James. La erigimos aquí portavoz de este tercer grupo de histéricas olvidadas, pero 
también de mujeres ocultadas, silenciadas. Si bien la figura de Alice ha sido tratada como un ejemplo más de que «a lo largo de la historia, la histeria ha servido como una forma de expresión, un lenguaje corporal para las personas que de otro modo podrían no ser capaces de hablar o incluso a admitir lo que sienten» (Showalter, 1997: 29); su excepcionalidad radica en dos hechos fundamentales: consiguió transgredir las normas impuestas, convirtiéndose por ello en una loca escritora -que no en una escritora loca- y su esfuerzo dio como resultado un maravilloso fruto, su Diario. Las enseñanzas vitales que en él plasmó son asombrosas, enriquecedoras y, sobre todo, bellas. Estudiemos su locura y su escritura.

\section{A modo de ejemplo: Alice James}

Alice James fue una histérica desde los diecinueve años de edad (James, 2003: 182). Su vida estuvo marcada por la inactividad, la postración y las pequeñas y contadas salidas al exterior (James, 2003: 69). Si bien es cierto que pudo disfrutar de un maravilloso viaje a Europa con su hermano Henry -el famoso novelista- y su amada tía Kate, esta aventura solo acrecentó el choque entre sus necesidades vitales, psicológicas, y sus posibilidades sociales y familiares (Strouse, 2011: 155172). Para hacernos una idea, entre sus grandes aventuras se encuentran el haber pasado un verano montando a caballo en la finca familiar, actividad física inusual para la pequeña James.

$\mathrm{Su}$ infancia, marcada por la inestabilidad familiar debido a sus continuos viajes (Feinstein, 1987), fue sin embargo menos interesante que la de sus hermanos: Alice debía permanecer en casa mientras ellos iban a la escuela, salvo en breves periodos en los que pudo disfrutar de la asistencia al colegio. Ya desde pequeña desarrolló síntomas de esta dolencia tan habitual en su época, como ella misma relata:

Debido a alguna debilidad física, un exceso de sensibilidad nerviosa, la capacidad moral se detiene, como por un momento, y se niega a mantener su cordura muscular, agotada por el esfuerzo de sus funciones de vigilancia. Cuando me sentaba inmóvil leyendo en la biblioteca y repentinamente invadían mis músculos oleadas de violentas inclinaciones que adoptaban alguna de su miríada de formas como arrojarme por la ventana, o romperle la cabeza al benigno páter con sus guedejas plateadas, sentado a su mesa escribiendo, me parecía que la única diferencia entre yo y un loco era que yo no sólo sufría todos los horrores y sufrimientos de la locura sino que también se me imponían las obligaciones del doctor, la enfermera y la camisa de fuerza (James, 2003: 189).

Analizando la compleja historia familiar y tomando su caso con la perspectiva del contexto social en el que vivió, estamos en disposición de apuntar la etiología de su dolencia. Entre las posibles causas, resaltan tres: la época, la familia y su disposición psicológica.

Por un lado, tal y como hemos visto, Alice vivió en una época de gran presencia de la histeria, identificada de diversos modos: 
Los médicos encontraron toda una variedad de etiquetas para diagnosticar la ola de invalidez que atenazaba a la población femenina: «neurastenia», «postración nerviosa», «hiperestesia», «insuficiencia cardiaca», «dispepsia», «reumatismo» e «histeria». Entre los síntomas había dolor de cabeza, dolores musculares, debilidad, depresión, dificultades menstruales, indigestión, etc., y normalmente una debilidad general que exigía reposo constante (Ehrenreich, 2010: 148).

Esta diversidad de denominaciones constituye una muestra en sí misma de la magnitud del problema. Aunque, al igual que durante el Medievo y el Renacimiento (Veith, 1965), esta dolencia no solo fue sufrida por mujeres, la intensidad de su manifestación femenina y su mayor presencia en este colectivo, hace que pueda hablarse de una enfermedad con tendencia de género. Por ejemplo, su hermano William sufrió también problemas nerviosos y neurastenia (Feinstein, 1987: 122 y ss.), pero no le impidió desarrollar una carrera académica que lo llevaría a ser un reputado profesor en Harvard y presidente de la American Psychological Association.

En este sentido, entonces, Alice fue una más entre tantas mujeres histéricas, si bien su postración fue especialmente dura. La situación económica de la familia resulta determinante para este grado de invalidez. Como miembro de la burguesía y soltera, Alice solo hubo de realizar trabajos domésticos durante el breve lapso de tiempo en el que su madre estuvo demasiado enferma para encargarse de la casa (murió el 19 de enero de 1882 tras una breve enfermedad) y los pocos meses hasta la muerte de su padre (el dieciocho de diciembre de 1882). Durante este periodo -curiosamente- la pequeña James no mostró síntomas histéricos. Sospechamos que el hecho de estar ocupada tuvo mucho que ver en esta ausencia.

El ambiente familiar fue otro factor determinante: mientras que los hermanos James gozaron de viajes, cultura y libertad, la pequeña de los cinco, Alice, permaneció en casa con muy pocas opciones. El progenitor, Henry James Sr., místico swedenborgiano, era profundamente misógino (Strouse, 2011: 45), hecho agravado en el caso de Alice por ser la más pequeña y única mujer de cinco hermanos. Ejemplo de ello es el episodio en que sufre un colapso nervioso tras serle denegado el permiso para visitar a una amiga durante dos días.

Las opciones vitales de Alice fueron nulas, acrecentadas por una suerte de economía de recursos, energéticos y económicos- que debían ser distribuidos entre todos los miembros (Strouse, 2011: 111). William, en una carta a un amigo, escribe: "cómo te envidio tu caudal de energía. Yo dispongo de una cucharadita para cada día y cuando se termina, cosa que usualmente sucede a las diez de la mañana, no sirvo para nada» (Perry, 1935: 1,373). Sus hermanos mayores, William y Henry, disfrutaron de la mayor parte de esos recursos, quedando para la genio de la familia, escasas opciones. Para Alice, tras haberle sido denegado el bautismo por los padres, y el matrimonio por «hombres obtusos e insensibles» (James, 2003: 261) solo quedó lo que se ha denominado «su trabajo de inválida» (Yeazell, 1981: 4).

La lección de vida que Alice siguió, en todo caso, fue: «emplearme a fondo entre los 12 y los 24 años, «matarme», como alguien lo llama, absorbiendo hasta la médula que lo mejor es vestirse con tonos neutros, caminar junto a aguas serenas y poseer tu propia alma en silencio» (James, 2003: 129). 
Esta necesidad de domesticación psicológica chocaba enormemente con el impetuoso carácter de Alice. Tanto mediante la lectura de su correspondencia, como en referencia de otros miembros de la familia, la pequeña se mostraba enérgica, tenaz y terca, con un duro carácter, al que William terminó por referirse como «relámpago embotellado» (James, 2003: 60). La pequeña James no dudaba en responder de forma «descarada» a los hermanos e incluso a su padre, quien habría tolerado «las exigencia de Alice de forma totalmente milagrosa», en palabras de la madre (Edel, 2003: 27 y ss.).

Hubo, entonces, de aniquilar su fuerte personalidad, hasta convertirse en «esa jovencita ociosa e inútil a quién tendremos que alimentar y vestir» (Henry James, en Strouse, 2011: 83-84). Esta «muerte» de su disposición psicológica, afortunadamente para la revisión histórica, no se hizo totalmente efectiva, tanto literal como metafóricamente. Pese a haber reflexionado sobre el tema, nunca llegó -por suertea suicidarse. El suicidio era propio de individuos débiles. Muestra Alice, de nuevo, su fortaleza.

En sentido metafórico, tampoco su «gran riqueza interior» se vio eliminada, sino que, tras años de silencio y postración, se decide a mostrar lo que ella misma denomina «el geiser de emociones y sensaciones» (James, 2003: 51) que la embargan, que habitan en el seno de «ese ser sumamente interesante, yo» (James, 2003: 51).

Su escritura es, por tanto, la de una loca escritora que hubo de esperar a que su progenitor muriese para emprender una nueva etapa en Inglaterra y decidirse a plasmarla. Su Diario constituye una compleja obra en la que se vierten comentarios políticos, reflexiones sobre los usos y costumbres de británicos y americanos, cotilleos y, sobre todo, una vida.

En las numerosas y cuidadas entradas de su Diario, Alice muestra su intimidad, partes de sí misma, de sus sentimientos y razonamientos, tanto como de su enfermedad que resultan a la vez ilustrativas y aterradoras. El más impactante suceso relatado es la evolución de la enfermedad que la llevó a la tumba: un cáncer de pecho, breve y muy doloroso que la narradora tomó como un gran regalo vital (James, 2003: 250). Gracias a él pudo poner nombre a la enfermedad; gracias a él pudo ser considerada no una «loca», una «inválida», sino una enferma (James, 2003: 250); gracias a él y de modo más fuerte que nunca, pudo sentirse viva.

Alice trabajó en su única obra, su Diario hasta el mismo día de su muerte, corrigiendo cada frase, mimando cada idea, poniendo en él todas sus energías y conocimientos recogidos de una larga vida de cama y lectura.

Tras su fallecimiento -el seis de marzo de 1892- su amiga y compañera Katherine P. Loring envió un ejemplar a cada uno de sus hermanos con el fin de poder cumplir el último deseo de Alice: que su obra fuese publicada. ¿Qué pasó entonces? ¿Cómo reaccionaron sus afamados, cultos y progresistas hermanos? Se opusieron a publicarlo, incluso William, quién había votado a favor de la incorporación de las mujeres a su universidad y se mostró avanzado a su época y defensor de los derechos humanos y de las mujeres durante toda su vida.

Esta diferencia es menos sorprendente, sin embargo, si consideramos algunos episodios que revelan el perfil psicológico de Alice. En sus últimos meses de vida, 
William le escribirá aconsejándole que utilice toda la morfina o calmantes que pueda necesitar, pese a saber que su hermana es reacia a tales tratamientos (Edel, 2003: 38). La respuesta de Alice a esta misiva fue la de una ejemplar mujer con una extraordinaria fuerza interior y resistencia moral $-\mathrm{y}$, por tanto, corporal- que dio lecciones a su querido hermano mayor hasta en los últimos momentos de su vida (Yaezell, 1981: 247).

En cuanto a Henry, acostumbrado a la amistad con mujeres de la talla de Wharton, fue también contrario a la publicación del Diario. En su respuesta a Katherine Loring afirma haber quemado su ejemplar y recomienda hacer lo mismo con todos ellos, pues teme que su fama se vea comprometida por las íntimas consideraciones personales de su hermana. Si bien es cierto que en el Diario se recogían anécdotas familiares y cotilleos variados que podían resultar molestos a algunas personas, también lo es que hubiese sido posible eliminar los nombres y ciertas referencias, manteniendo con ello el deseo de la autora de que su obra fuese publicada.

Por una parte, Henry escribe a William reconociendo que Alice no disfrutó de la posibilidad de dejar ver su extraordinaria energía, inteligente personalidad y aptitudes morales (Strouse, 2011: 319). Sin embargo, por otro lado, se opone a la publicación de la obra y quema su copia junto a correspondencia y otros documentos relacionados con su hermana. Si a esto añadimos, además, afirmaciones de Henry como: «simplificaba demasiado, encerrada en su enfermería, aplicaba su extraordinario vigor de juicio a un fragmento excesivamente pequeño de lo que realmente la rodeaba» (Edel, 2003: 42); la balanza se inclina nuevamente hacia el paternalismo o la vergüenza (Gordon, 1999: 251).

Lo público -la imagen de William y Henry en su sociedad y su paso a la posteridad-y lo privado -cómo gestionaban los asuntos familiares y el trato que dieron a su hermana- chocan. Debemos, entonces, ser cautos en nuestro análisis de un tema tan delicado como la histeria y las cuestiones psicológicas, grupales y sociales que la han envuelto. Solo así, yendo al fondo de este histórico problema, podremos acabar con él.

\section{La superación de los límites}

Antes de tomar en consideración la importancia que Alice puede tener para nosotros en la actualidad es necesario sacar a la luz su significación histórica. Para ello apuntaremos los principales hitos de superación de los límites establecidos que hemos estructurado en cinco puntos principales desde su punto de vista personal y biográfico hasta el impacto social de sus transgresiones. Alice va más allá de unos límites que son demasiado estrechos para un carácter como el de Alice, pero también para cualquier ser humano y se supera a sí misma y los padecimientos psicológicos que la sociedad le había impuesto mediante la escritura. Alice puede ser concebida, en este sentido, bajo lo que Yaeger ha descrito como «interés emancipador vertido sobre el propio lenguaje» (1988: 43), en tanto que sus caracterizaciones y análisis, así como la actividad de escritura en sí misma, son liberadores para ella, pero también para el conjunto de las mujeres. 
En este sentido, Alice se vuelve un modelo de todas aquellas mujeres reprimidas que aportaron un pequeño grano de arena en la lucha por su reconocimiento y su liberación. El ejemplo de la pequeña de los James es si cabe más sobresaliente, no en cuanto a su significado histórico, sino más bien en relación a su legado: su Diario, que constituye una obra clave para la comprensión de su vivencia, su enfermedad y la sociedad que fomentó, por no decir obligó a que su vida fuese la de una inválida en su enfermería.

El primer y más sobresaliente elemento de superación de estos límites impuestos a Alice lo constituye sin duda la propia escritura de su Diario. Tradicionalmente la escritura, como cualquier acto público o de exposición hacia el exterior ha sido considerada una tarea masculina. El hecho, entonces, de que Alice escribiese su obra transgrede los límites socialmente admitidos.

Psicológica y vitalmente hablando, sin embargo, Alice no solo transgrede, sino que supera los límites que la sociedad le había impuesto de mantenerse callada. La escritura del Diario es un ejercicio de desarrollo personal y de expresión que actúa al modo de terapia psicológica. Alice, mujer fuerte y bastante independiente, será su propia terapeuta a lo Freud, puesto que con la escritura mejora su condición humana al escribir para un público y sentirse arropada y aceptada; y el gran sufrimiento psicológico que había padecido desde la imposición de los primeros corsés sociales y familiares durante su infancia.

Junto a ello, nuestra protagonista está poniéndose en los límites mismos de su familia, en tanto en cuanto no tiene importancia que escriba, sino que su Diario cobra relevancia en el momento en que Kate anuncia que ella deseaba que fuese publicado. Con ello, con este hecho que se vuelve reivindicativo, Alice podría convertirse en una persona visible, dejando de desempeñar su tarea de inválida. El Diario pasa entonces, a ojos de sus hermanos, de ser terapéutico (Feinstein, 1987: 253) a constituir un problema, como vimos. Además, aunque el progenitor había fallecido, el deseo de publicación de Alice, así como el ejercicio mismo de escribir, va contra la educación misógina que había recibido, rompiendo con ello los límites que la familia había establecido.

Otro de los puntos en los que la pequeña de los James toca o pasa los límites de lo permitido es en relación a los contenidos de su Diario. Lejos de ser una mera colección de anécdotas -que también abundan- Alice plasma usos y costumbres de la sociedad británica, los compara con la americana y establece juicios críticos al respecto (James, 2003, 41). Pero, además, nos brinda la posibilidad de conocer a fondo sus experiencias, sensaciones y emociones, algo que en la sociedad victoriana está lejos de permitirse o ser socialmente aceptable.

El modo en que Alice recoge la vivencia de su histeria y cómo la contrasta con su enfermedad «real», "palpable», su cáncer de pecho, constituye una crónica interna, pero nada inocente de qué supone ser una histérica tanto a nivel social como psicológico y personal. Alice transgrede los límites sociales y académicos de la nueva ciencia psicológica al contraponer su propia consideración del cáncer como una enfermedad real a la histeria que sufría. Lejos de la configuración masculina de la histeria, Alice retrata su propia «vida» a través de la invalidez de modo que nos 
permite comprender la significación masculina de esta dolencia atribuida socialmente a la mujer. Nuevamente, la definición médica dominada por hombres establece los límites de lo permitido y Alice va más allá de ellos proponiendo su propia clasificación y su punto de vista como paciente.

Un último punto que nos gustaría apuntar antes de pasar a las consideraciones finales es la relación abierta de Alice con una mujer: Katherine Peabody Loring, quien la cuida y ayuda hasta el último momento con una «infinita paciencia» (James, 2003, 297). Si bien no ha trascendido si se trata de su pareja sentimental, el tipo de relación establecido por las dos mujeres así lo parece. Alice se posicionaría, entonces, en el límite: tanto si mantenía una relación lésbica como si hizo de Kate su mejor amiga y compañera inseparable, establece en su vida una tensión con la sociedad victoriana en la que, como vimos, el matrimonio era el destino de las mujeres. Dos compañeras, mujeres, se sitúan -pese a la discreción del caso- en el límite de lo permitido.

No entraremos a considerar la extraña y profunda relación que Alice tuvo con la muerte, momento que concibió como un regalo y la oportunidad de sentirse viva, de ser una persona completa, normal, según los cánones establecidos. Alice hace de su muerte su bien más preciado, estableciendo una relación antitética con ella que, dada su complejidad, no es posible tratar en el presente texto, habiendo sido ya tratado (López Vale, 2014).

En todo caso, Alice fue una transgresora, una mujer fuerte y que nos sirve de modelo para comprender cómo los más pequeños actos cobran la máxima importancia si son ejecutados en los límites de lo permitido o, como hemos visto, más allá de ellos. Pensemos, además, que aunque estas transgresiones y superaciones personales puedan parecer restrictas al caso concreto de Alice, suponen un ejemplo de oposición a grandes hitos masculinos como la medicina o la esfera pública, por lo que no han de ser desdeñados, sino servir de punto de partida para reflexionar sobre el tratamiento de las mujeres a lo largo de la historia, pero, y sobre todo, en el presente.

En el siguiente y último apartado, analizaremos de qué modo la histeria sigue vigente a día de hoy, pasando posteriormente a extraer aquellos puntos más característicos de Alice, a quién hemos tomado como ejemplo y referente. Antes de finalizar, además, señalaremos la importancia de rescatar, visibilizar, a las mujeres que han caído en el olvido, pese a haber aportado su grano de arena en la lucha feminista, como el caso de nuestro modelo.

\section{Consideraciones finales: ¿qué hemos aprendido?}

La histeria se ha declarado extinta a día de hoy. Sin embargo, buena parte de las actitudes que históricamente se han relacionado con esta enfermedad, perviven. Me refiero con ello al proceder de la sociedad con aquellas mujeres que van más allá de los cánones de normalidad establecidos. Todavía hoy, pese a disfrutar de una mayor libertad y derechos, las mujeres no deben sobresalir, ni personal ni laboralmente. El llamado techo de cristal continúa siendo una realidad reflejada 
en las diferencias salariales y el acceso a altos cargos. En el ámbito doméstico, por desgracia, aumenta la percepción masculina de poseer un objeto, debiendo dominarlo. Solo en España, el número de mujeres asesinadas a manos de sus maridos en el año 2015 asciende a sesenta (Portal Estadístico Ministerio de Sanidad). Algo falla.

Por un lado, en nuestro breve recorrido hemos podido constatar cómo la histeria es un problema impuesto a la feminidad, un modo de marginalización, estigma y control social de las estructuras de poder dominante: las masculinas. En este sentido, resultan ilustrativos los estudios foucaultianos acerca de estos mecanismos de control social e higiene (Foucault, 1976; Foucault, 2012). Para el caso de Alice, según revela de su hermano Henry, «la trágica salud [de Alice] era, en cierto modo, la única solución que ella veía al problema práctico de su vida» (Edel, 2003: 30-31).

Pese a esta parca experiencia Alice resulta de lo más sugerente a día de hoy en varios aspectos: por un lado, muestra la lucha tanto interna como externa, pública, a través de una tarea como la escritura que ha sido tradicionalmente asociada a lo masculino; esto, además, vertido en la redacción de un diario por parte de una mujer con tan escasas posibilidades vitales cuyo deseo era que su obra fuese publicada.

Por otro, muestra esa sutil manera en la que el poder invalida, somete a las mujeres. Si bien en el caso de Alice y su tiempo no nos resulta tan sutil debida a nuestra visión retrospectiva, debemos pensar que en su época las mujeres comenzaban a tener posibilidades de desarrollo. Por tanto, quizás se sintiesen más liberadas que nunca, y así debía ser, pese al elevado grado de control al que estaban sometidas. Hoy, sostenemos, ocurre lo mismo: nos creemos libres, pero seguimos estando coartadas por una sociedad que continúa siendo fundamentalmente masculina en cuanto a las jerarquías de poder.

Perdurando en su acepción tradicional, el adjetivo de «histérica» sigue siendo atribuido tan sólo a mujeres para denotar un supuesto nerviosismo intrínseco, ligado implícitamente con su sexualidad y debilidad psicológica para desclasificar, en cualquier caso, toda acción que se salga de lo habitual. Es un uso cotidiano que pasa prácticamente desapercibido, pero que no es en modo alguno inocente. Ha de ser erradicado.

Así, pese a algunos avances nada desdeñables como el hecho de que la escritura ya no pertenezca al ámbito de lo masculino, continúa vigente como ideología que si una mujer quiere ser poderosa, adaptarse y estar bien considerada, o es como-unhombre en el terreno público o vive como-una-mujer en la intimidad del hogar. En caso contrario, la jerarquía de poder impide que llegue a escalar en ella mediante ese conocido «techo de cristal».

Por tanto, autoras como Alice son representativas de una intención que no ha de ser menospreciada: la libertad de expresión y de vivir -en este caso mediante la alegría de morir (López Vale, 2014: 29) más allá de los mandatos masculinos y las opciones que son brindadas a las mujeres. Además, su Diario constituye un gran instrumento para el conocimiento de la histeria, de cómo ésta se configuraba y qué implicaciones humanas traía aparejadas. Así, más allá de una banal teoría machista, su obra constituye un ejemplo desde dentro del propio problema, de cómo era 
vivido ser una histérica decimonónica. La viveza de sus descripciones es igualmente ilustrativa y sobrecogedora.

Además, Alice nos permite ir un paso más allá al hacernos conscientes de una reflexión que queda usualmente oculta: la pervivencia de la imagen de las locas escritoras: la asociación de que aquellas que se atrevían a escribir no eran mujeres normales, sino desviadas, patológicas (Canguilhem, 2005), locas. Esto ocurre, como hemos visto, pese a mostrar una madurez más allá de las divisiones de género que puedan ser establecidas, una verdadera «autor-mayoría de edad» en el sentido ilustrado (Kant, 2012).

A través de Alice James hemos podido, además, hacer ver una de las fallas historiográficas más importantes que se nos presentan: la escasa o nula visibilización de las mujeres. Alice, como tantas otras mujeres que han aportado su grano de arena a la historia de la humanidad, está prácticamente olvidada. En este trabajo se ha intentado paliar, modestamente, este olvido, presentando a una mujer escritora y transgresora, que supo superar las trabas impuestas socialmente para morir feliz consigo misma, sintiéndose viva y dejándonos su Diario como legado.

El presente artículo supone un pequeño paso en un largo camino de desocultación y descubrimiento de las mujeres, así como de eliminación de las desigualdades, incoherencias e injusticias que todavía enfrentamos. El trabajo, sin embargo, está aún por hacer. Mediante el ejemplo de Alice hemos abierto una interesante vía de análisis que, sin duda, nos ayudará en nuestra tarea. Una tarea, recordémoslo, de todos y no solo de todas.

\section{BIBLIOGRAFÍA}

Amstrong, Nancy (1991): Deseo y ficción doméstica. Una historia política de la novela, Madrid, Cátedra, 1987 (traducción de María Coy).

BLum, Deborah (2007): Ghosts Hunters. William James and the Search for Scientific Proof of Life After Death, London, Penguin Books.

Canguilhem, George (2005): Lo normal y lo patológico, México D.F., Siglo XXI, 1943 (traducción de Ricardo Potschart).

De BINGEN, Hildegarda (2009): Vida y visiones de Hildegard von Bingen, Madrid, Siruela, s.a. (traducción de Victoria Cirlot).

Demóstenes (1978): Demosthenis orationes, Cambridge, Cambridge University Press, s.a. (traducción de Jonh A. Vince).

DupeE, Frederick W. (1951): Henry James, London, Methuen.

EDEL, Leon (1953-1972): Henry James, 5 vols., Philadelphia, J. B. Lippincott Company.

EHRENREICH, Barbara (2010): Por tu propio bien. 150 años de consejos expertos a mujeres, Madrid, Capitán Swing Libros, 2003 (traducción de M $^{a}$ Luisa Rodríguez Tapia). - (2008): Una historia de la alegría, Barcelona, Paidós.

FeInsteIn, Howard M. (1987): Becoming William James, USA, Cornell University Press. FIsHer, Paul (2008): House of Wits: An Intimate Portrait of the James Family, Henry Holt and Co., USA.

Foucault, Michel (1964): Enfermedad mental y personalidad, Buenos Aires, Paidós, 1954 (traducción de Emma Kestelboim). 
- (1976): Historia de la locura en la época clásica, México, Fondo de Cultura Económica, 1961(traducción de Juan José Utrilla).

- (1978): Historia de la sexualidad, Madrid, Siglo XXI, 1976 (traducción de Ulises Guiñazú).

- (2006): Los Anormales, México, FCE, 1999 (edición de Horacio Pons).

- (2007): Un diálogo sobre el poder y otras conversaciones, Madrid, Alianza, 1980 (traducción de Miguel Primera).

- (2012): Vigilar y castigar, Madrid, Biblioteca Nueva, 1984 (traducción de Aurelio Garzón del Camino).

Fowler, Virginia C. (1984): Henry James's American Girl, USA, The University of Wisconsin Press.

Galeno (1997): De locis affectis, Madrid, Ediciones Clásicas, s.a. (traducción de Ma del Carmen García Sola).

- (1952): On the Natural Faculties, Cambridge, Harvard University Press, s.a. (traducción de Arthur John Brock).

- (1968): On the Usefulness of the Parts of the Body, Ithaca, Cornell University Press, s.a. (traducción de John Redman Coxe).

GARrison, Fielding H. (1963): An Introduction to the history of medicine, Philadelphia, W. B. Saunders Company.

Goffman, Erving (1998): Estigma: la identidad deteriorada, Buenos Aires, Amorrortu, 1963 (traducción de Leonor Guinsberg).

Hipócrates (2003): Tratados Hipocráticos, Madrid, Gredos (traducción de Carlos García Gual).

Holly, Carol (1995): Intensely Family. The Inheritance of Family Shame and the Autobiographies of Henry James, Madison, The University of Wisconsin Press.

JAMEs, Alice (2003): El diario de Alice James, edición y estudio introductorio «Retrato de Alice James» de Leon Edel, págs. 23-46, Valencia, Pre-Textos, 1964 (traducción de Eva Rodríguez-Halffter).

Jantzen, Grace (1995): Power, Gender, and Christian Mysticism, Cambridge, Cambridge University Press.

KANR, Inmanuel (2002): ¿Qué es Ilustración?, Madrid, Taurus, 1784 (traducción de Roberto R. Aramayo).

Karras, Ruth M. (2005): Sexuality in Medieval Europe, Londres, Routledge.

KrAmer, Heinrich, y SPREnger, Jacob (2006): Malleus maleficarum, Londres, Cambridge University Press, 1484 (traducción de Christopher S. Mackay).

LAQUEUR, Thomas (1994): La construcción del sexo, Cátedra, Madrid, 1990 (traducción de Eugenio Portela).

Le Doeuff, Michèle (1993): El estudio y la rueca, Madrid, Cátedra, 1989 (traducción de Oliva Blanco Corujo).

LuCKHURST, Roger (2002): The Invention of Telepathy (1870-1901), Oxford, Oxford University Press.

López VAle, Alma (2014): «Alice James y la muerte como modo de salir al camino de la vida», Dossiers Feministes, N 18, Castellón de la Plana, pp. 21-33. 
MACKAY, Charles (1972): Memoirs of Extraordinary Popular Delusions, London, Richard Bentley, 1841.

Mathiessen, Francis O. (2008): The James Family. A Group Biography, New York, The Overlook Press.

Mathieu, Nicole-Claude (1991): L'anatomie politique. Catégorisations et idéologies du sexe, Paris, Côte-femmes.

Mitre, Emil (1998): Historia de la Edad Media, Barcelona, Ariel (traducción de Jose Ángel García de Cortázar).

Mommsem, Theodor (1983-1988): Historia de Roma (5vols.), Madrid, Turner, 18941908 (traducción de Alejo García).

Montiel, Luis (2006): «Síntomas de una época: magnetismo, histeria y espiritismo en la Alemania romántica», Asclepio LVIII (2), Madrid, CSIC, pp. 11-38.

Moore, R. Laurence (1977): In Search of White Crows. Spirigualism, Parapsychology, and American Culture, New York, Oxford University Press.

Moore, Robert I. (1987): The Formation of a Persecuting Society, Oxford, Blackwell.

PATEMAN, Carole (1996): "Críticas feministas a la dicotomía público/privado», en CASTELLS, Carme (comp.), Perspectivas feministas en teoría política, Barcelona, Paidós, pp. 2-23.

Pickren, Wade, y Rutherford, Alexandra (2010): A History of Modern Psychology in Context, New York, Wiley.

Portal Estadísitico del Ministerio de Sanidad (2016): http:/ /estadisticasviolenciagenero.msssi.gob.es, consultado el día 7 de enero de 2016.

Ebell, B. y BANov, Leon (1937): The Papyrus Ebers, the Greatest Egyptian Medical Document, Copenhague, Levin y Munksgaard, s.a. (traducción de B. Ebbell).

SÁnchez Ortega, María Helena (1992): La mujer y la sexualidad en el Antiguo Régimen. La perspectiva inquisitorial, Madrid, Akal.

Scull, Andrew (Ed.)(1981): Madhouses, Mad-Doctors and Madmen: The Social History of Psychiatry in the Victorian Era, Philadelphia, University of Pennsylvania Press.

SEgURA I SORIANO, Isabel (1987): «La literatura de mujeres como fuente de documentación para la recuperación de la experiencia histórica de las mujeres», en VVAA, Literatura y vida cotidiana, Zaragoza, Universidad Autónoma de Madrid Ed.

Sigerist, Henry E. (1943): Civilization and Disease, Chicago, University of Chicago Press.

Simon, Bennett (1978): Mind and Madness in Ancient Greek, Ithaca and London, Cornell University Press.

SKInNer, Marilyn B. (2005): Sexuality in Greek and Roman Culture, Massachusetts, Malden.

ShowAlter, Eloine (1985): The Female Malady: Women, Madness, and English Culture, 1830-1980, New York, Pantheon.

- (1997): Hystories, New York, Columbia University Press.

Strouse, Jean (2011): Alice James, A biography, New York, New York Review Book. TurRó, Savio (1985): Descartes. Del hermetismo a la nueva ciencia, Barcelona, Anthropos. VeITH, Itza (1965): Hysteria, Chicago y Londres, The University of Chicago Press. 
WARren, Austin (1934): The Elder Henry James, New York, Macmillan.

WHARTON, Edith (1997): Una mirada atrás, Barcelona, Ediciones B., 1934 (traducción de Jordi Gubern).

YAEger, Patricia (1988): Honey-Mad Women: Emancipatory Strategies in Women's Writing. New York, Columbia University Press.

YeazeLL, Ruth. B. (1981): Death and Letters of Alice James, Berkeley, University of California Press.

Recibido el 1 de diciembre del 2015

Aceptado 3 de noviembre de 2016 BIBLID [1132-8231 (2016): 145-160] 